\title{
Mineração
}

\section{Definição e plano de produção de um depósito típico de níquel laterítico aproveitado através de rota de lixiviação ácida sob pressão}

\author{
(Definition and production plan for \\ a PAL lateritic nickel deposit)
}

Ruy Lacourt Rodrigues

Engenheiro de Minas, Universidade Federal de Ouro Preto

E-mail: ruy.lacourt@vale.com

Valdir Costa e Silva

Professor Associado, Universidade Federal de Ouro Preto

E-mail:valdir@demin.ufop.br

\section{Resumo}

Definiu-se um depósito hipotético de níquel laterítico de tamanho médio a partir dos dados dos projetos em desenvolvimento e implementação.

Estabeleceram-se os planos de produção para uma operação com aproveitamento do depósito através de rotas de processo de lixiviação ácida sob pressão, respeitando-se parâmetros que se observam na indústria. Estudaram-se escalas de produção entre 45000 t/ano Ni e 300000t/ano Ni, estabelecendo-se indicadores técnicos que foram utilizados para avaliação de capacidade.

Palavras-chave: Plano de produção, definição de capacidade, níquel laterítico, lixiviação ácida sob (alta) pressão (PAL, HPAL, HiPAL).

\begin{abstract}
A hypothetical lateritic nickel deposit of median size was defined using data from a number of deposits under development and implementation.

Production plans for a pressure acid leach operation were developed using industry parameters. Capacities between 45000 t/year Ni and 300000 t/year Ni were studied, leading to a set of technical parameters, used for capacity assessment.
\end{abstract}

Keywords: Production plan, capacity definition, lateritic nickel, (high) pressure acid leaching (PAL, HPAL, HiPAL). 


\section{Introdução}

As lateritas de níquel, em especial aquelas em que o aproveitamento é feito através de rotas de lixiviação ácida sob pressão, são a maior fonte potencial para o crescimento da oferta do metal e os projetos em desenvolvimento e implementação que utilizam essa tecnologia constituem a parcela mais expressiva da capacidade a ser colocada no mercado nos próximos anos.

$\mathrm{O}$ aproveitamento de níquel laterítico através de rotas de lixiviação ácida sob pressão (em inglês: pressure acid leaching - PAL, também, high-pressure acid leaching - HPAL, HiPAL) foi desenvolvido no final da década de $50 \mathrm{e}$, primeiramente, aplicado em Moa Bay, Cuba, que permaneceu, por muitos anos, como a única operação a utilizar esta rota de processo. A tecnologia foi retomada no final da década de 90 com a implementação de três operações na Austrália Ocidental. Um esquema simplificado do processo é mostrado na Figura 1.

A Figura 2 mostra a planta de Murrin Murrin, da Minara Resources, na Austrália Ocidental.

O minério é alimentado na planta e segue para a lixiviação ácida em autoclaves sob alta temperatura e pressão. $\mathrm{O}$ ácido sulfúrico dissolve o $\mathrm{Ni}$ e Co em conjunto com uma série de outros metais.

Na neutralização primária, a adição de calcário à temperatura e pressão ambientes aumenta o $\mathrm{pH}$ da solução, precipitando $\mathrm{Fe}, \mathrm{Al}$ e $\mathrm{Cr}$ através de decantação em contracorrente. É feita uma neutralização secundária, com cal, para a remoção de Fe residual e $\mathrm{Cu}$ e correção do $\mathrm{pH}$, e os rejeitos são enviados à barragem.

A solução clarificada da neutralização primária segue para a precipitação de um produto intermediário - hidróxido ou sulfeto misto de Ni e Co impuro - com cerca de $50 \%$ de $\mathrm{Ni}$, que é refinado ao catodo.

O cobalto é um subproduto importante do aproveitamento de níquel laterítico através das rotas hidrometalúrgicas.

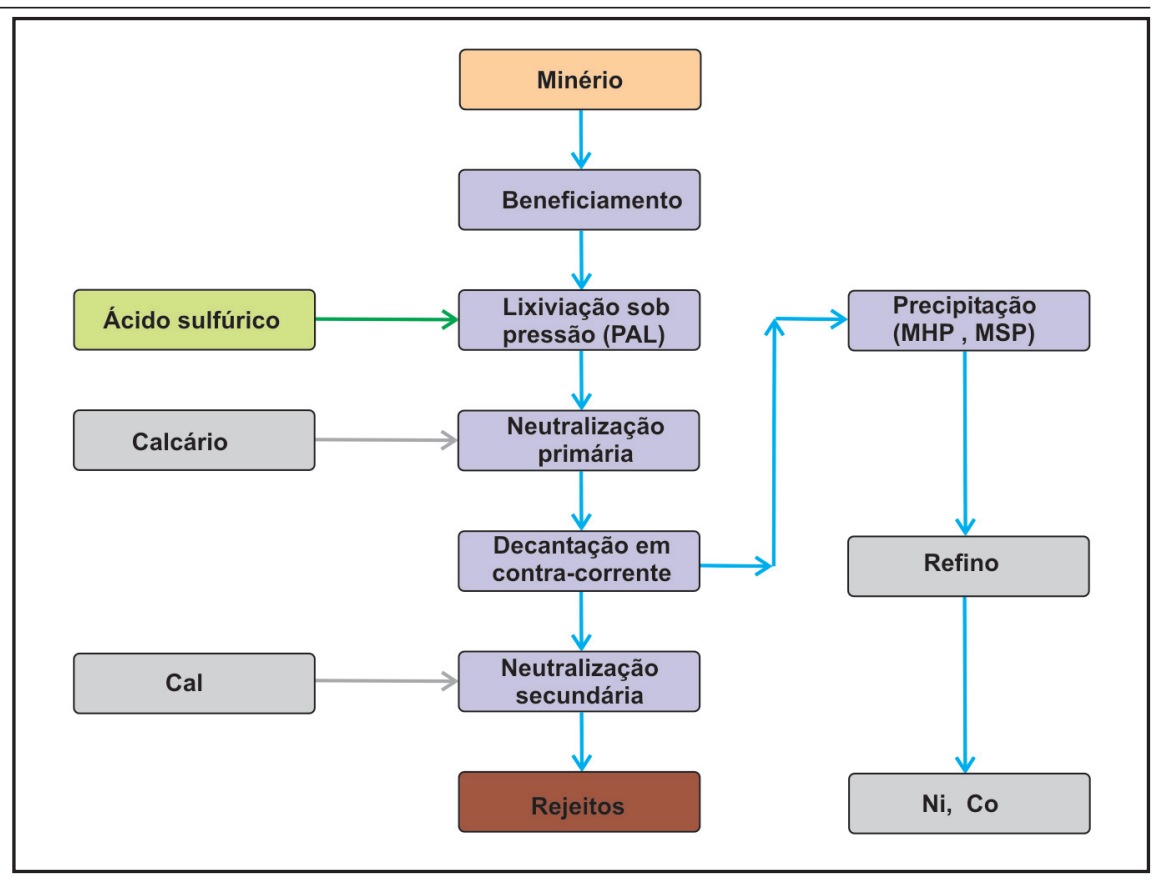

Figura 1 - Diagrama simplificado do processo de lixiviação sob pressão.

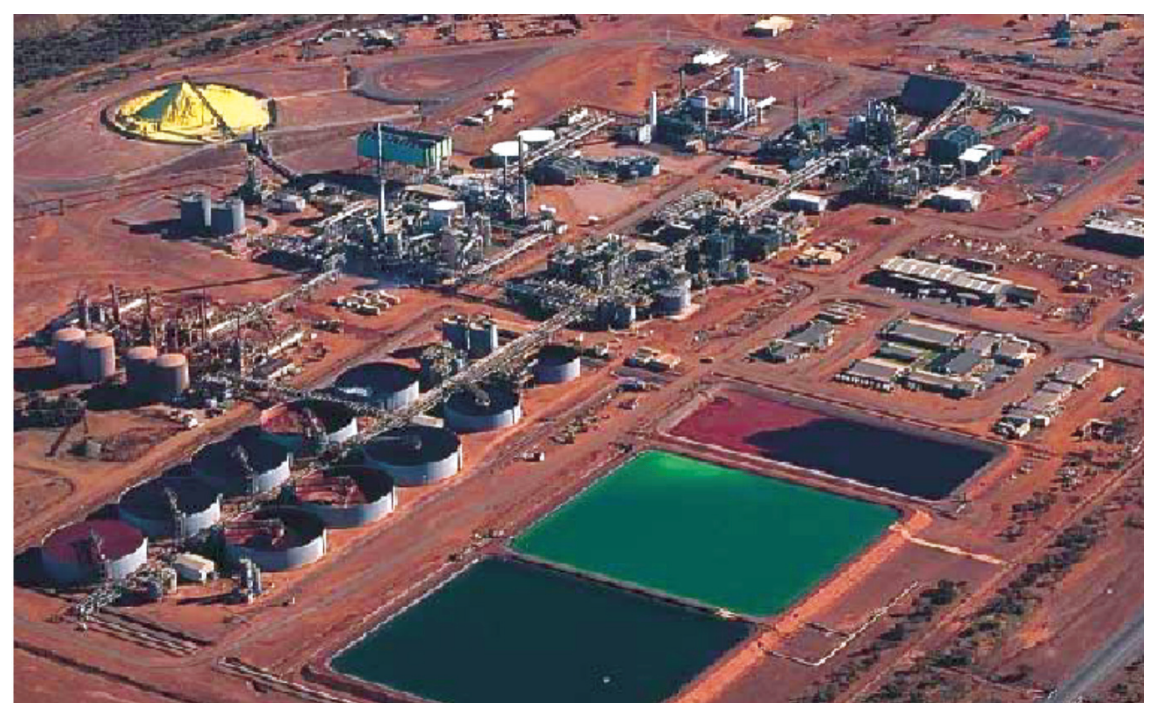

Figura 2 - Visão da planta de Murrin Murrin. Fonte: Anaconda Nickel (2002).

\section{Metodologia, resultados e discussão} 2.1 Definição do depósito
típico e inventário de reservas

\section{Tamanho do depósito}

Uma relação de depósitos de Ni laterítico apresentada pelo USGS (USGS, 2003) foi estudada, selecionando-se os projetos em que o aproveitamento será feito através de rota hidrometalúrgica, correspondentes aos depósitos em que há predominância de minérios limoníticos, ou aqueles cuja rota ainda não foi definida. Foram excluídos, portanto, os projetos cuja rota já tenha sido definida como sendo através de processos pirometalúrgicos, correspondentes a depósitos em que predominam minérios saprolíticos.

Essa seleção define um perfil para o depósito-tipo no qual os teores de níquel são, em geral, mais baixos, refletin- 
Ruy Lacourt Rodrigues et al.

do com maior aderência as condições de aproveitamento dos projetos cuja rota de processo é de lixiviação sob pressão.

A Figura 3 mostra o conteúdo metálico e os teores das reservas mais recursos inferidos para o conjunto de depósitos em estudos e implementação.

Adotaram-se como referência para o tamanho do depósito-tipo, a mediana da soma da tonelagem de reservas mais recursos inferidos e a mediana do conteúdo metálico de $\mathrm{Ni}$ e Co encontrada para o conjunto de depósitos selecionados.

\section{Inventário de reservas}

As espessuras das unidades litológicas que compõem o depósito e os teores de $\mathrm{Ni}, \mathrm{Co}, \mathrm{Fe}$ e $\mathrm{Mg}$ nas várias unidades foram definidas a partir de um perfil típico de depósitos de Ni laterítico apresentado por Elias (2002, p. 4 e p. 7), desenvolvendo-se a Tabela 1 e a Tabela 2 , o que define o inventário de reservas.
Os teores adotados para os elementos são mostrados na Tabela 1.

Calculando-se as massas dos elementos a partir de seus teores, estabeleceram-se os conteúdos metálicos relativos a cada elemento e a massa de todo o depósito foi fatorada, de forma que a tonelagem total e os conteúdos metálicos de Ni e Co correspondessem aos valores medianos.

O inventário de reservas resultante é mostrado na Tabela 2.

Os teores de níquel e cobalto resultantes para o depósito estudado são inferiores àqueles da mediana do conjunto de depósitos selecionados - $24 \%$ e $16 \%$ menores. O estabelecimento da referência com relação ao conteúdo metálico assegura maior aderência ao comportamento provável dos depósitos existentes quando venham a ser aproveitados, do que se a referência fosse estabelecida com relação ao teor.

\subsection{Plano de aproveitamento}

O plano de aproveitamento e o seqüenciamento de produção foram estabelecidos a partir do inventário de reservas. Foram feitos estudos de aproveitamento para cinco escalas de produção diferentes (em 1000 t/ano Ni): 45, 60, 120, 200 e 300 .

A estratégia de seqüenciamento de produção obedece às várias restrições simultâneas quanto à capacidade das seguintes unidades do sistema, enumeradas por ordem de importância:

- Lixiviação $(P A L)$.

- Refinarias de Ni e Co.

- Planta de ácido.

- Planta de beneficiamento.

- Lavra.

A fim de antecipar fluxos de caixa mais elevados, maximizando o aproveitamento dos recursos, foi implementada uma estratégia através da imposição de teores de corte mais elevados no início

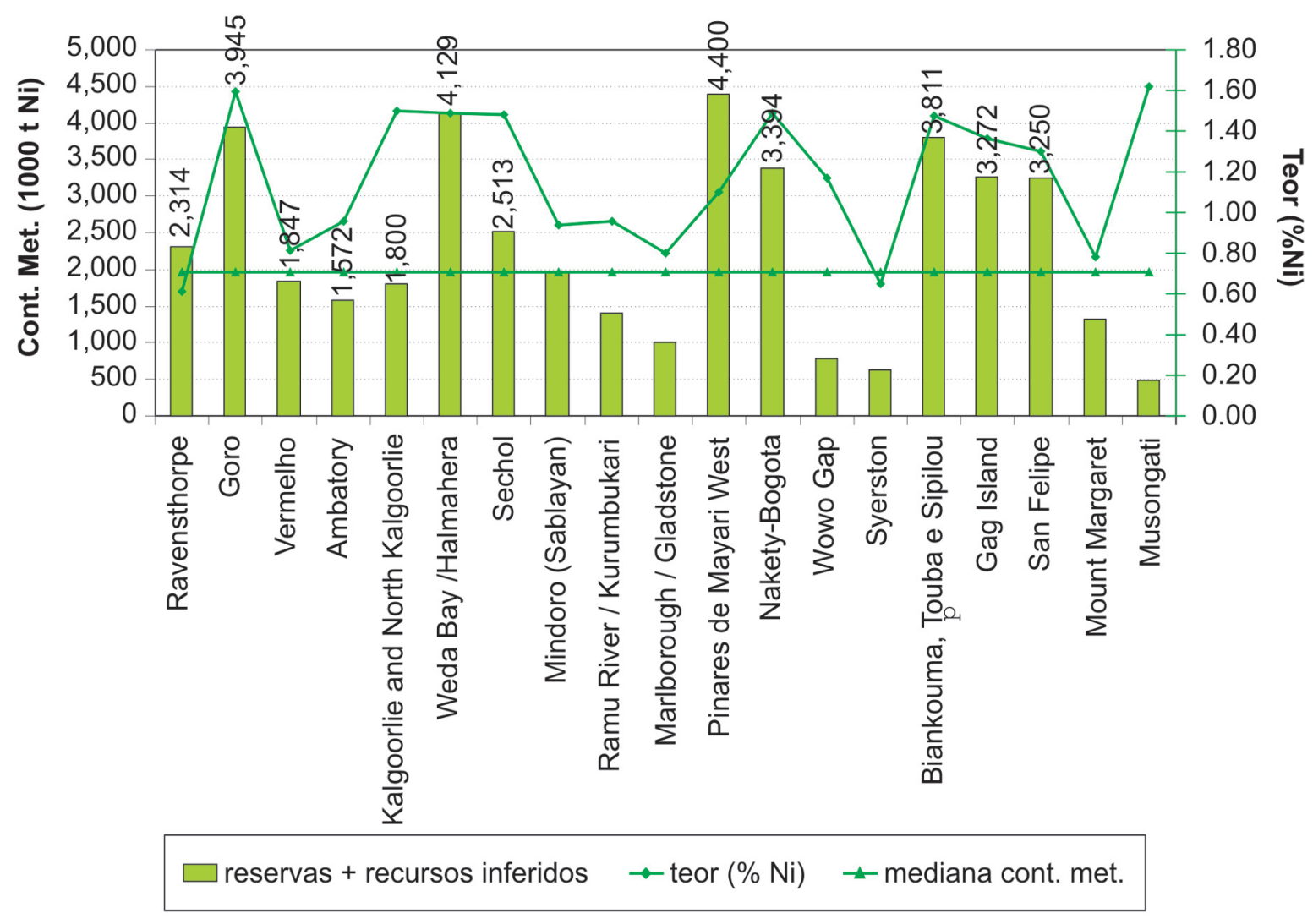

Figura 3 - Reservas e recursos inferidos dos depósitos em estudos e implementação. Adaptado de USGS (2003, op. cit.). 
Definição e plano de produção de um depósito típico de níquel laterítico aproveitado através de ...

Tabela 1 - Reservas do depósito típico - teores.

\begin{tabular}{c|c|c|c|c|c|c|c}
\hline Litologia & $\begin{array}{c}\text { Espessura } \\
(\mathbf{m})\end{array}$ & $\mathbf{N i} \%$ & $\mathrm{Co} \%$ & $\mathrm{FeOx} \%$ & $\mathbf{M g} \%$ & $\mathrm{Si} \%$ & Outros \\
\hline Limonita vermelha & 15 & 0.45 & 0.051 & 54 & 0.2 & 17.8 & 8 \\
\hline Limonita ocre & 15 & 0.84 & 0.103 & 44 & 1.8 & 20.8 & 7 \\
\hline Transição & 3 & 2.23 & 0.051 & 28 & 5.4 & 14.4 & 30 \\
\hline Saprolito & 7 & 1.67 & 0.051 & 11 & 12.7 & 16.9 & 30 \\
\hline Rocha fresca & & 0.30 & & 7 & 27.1 & 17.6 & \\
\hline Total/média & $\mathbf{4 0}$ & $\mathbf{0 . 9 4}$ & $\mathbf{0 . 0 7 1}$ & $\mathbf{4 1}$ & $\mathbf{3 . 4}$ & $\mathbf{1 9}$ & \\
\hline Mediana & & $\mathbf{1 . 1 7}$ & $\mathbf{0 . 0 8 2}$ & & & &
\end{tabular}

Tabela 2 - Tamanho do depósito típico.

\begin{tabular}{c|c|c|c|c|c}
\hline Parâmetro & $\begin{array}{c}\text { Tonelagem } \\
(\mathbf{M t})\end{array}$ & $\begin{array}{c}\text { Teor de Ni } \\
(\% \mathrm{Ni})\end{array}$ & $\begin{array}{c}\text { Ni contido } \\
(\mathbf{M t ~ N i})\end{array}$ & $\begin{array}{c}\text { Teor de Co } \\
(\% \mathrm{Co})\end{array}$ & $\begin{array}{c}\text { Co contido } \\
(\mathbf{M t} \text { Co) }\end{array}$ \\
\hline $\begin{array}{c}\text { Valor mediano para os } \\
\text { depósitos em estudos e } \\
\text { implementação }\end{array}$ & 208 & 1,17 & 1955 & 0,082 & 0,147 \\
\hline Valor adotado & $\mathbf{2 0 8}$ & $\mathbf{0 , 9 4}$ & $\mathbf{1 9 5 5}$ & $\mathbf{0 , 0 7 1}$ & $\mathbf{0 , 1 4 7}$ \\
\hline Diferença & $0 \%$ & $-24 \%$ & $0 \%$ & $-16 \%$ & $0 \%$ \\
\hline
\end{tabular}

da operação, os quais decrescem com o tempo (Lane, 1988), resultando um teor médio de alimentação e, por conseqüência, um patamar de produção, inicialmente mais altos.

A estratégia está fundamentamentada na baixa proporção dos custos de lavra no total dos custos. Utilizou-se uma taxa de lavra de cerca de $150 \%$ daquela da alimentação da planta, o que visa a expor e a alimentar a planta de maior quantidade de minério das unidades mais ricas - que estão na base do depósito mais cedo. Assim, as unidades mais ricas - o saprolito da base e o material de transição sobreposto - são utilizadas para alimentação direta, estocando-se os excedentes de limonita, que são alimentados pela planta no final da vida do empreendimento.

O perfil de produção na lavra para a escala de 45000 t/ano Ni é mostrado na Figura 4.
Portanto a lavra é feita em 32 anos, para um aproveitamento do depósito feito em 53 anos (até o ano 56).

Considerada a recuperação da hidrometalurgia - 90\% -, resulta o perfil de produção de $\mathrm{Ni}$ metálico mostrado na Figura 5, onde se verifica que a contribuição das unidades mais ricas é muito maior que aquela das limonitas do topo do depósito, razão do aproveitamento destas últimas ser postergado. Por outro lado, a capacidade da planta de ácido - e os custos deste - limitam a alimentação das unidades mais ricas, que têm mais Mg.

Na primeira fase da operação, em que se alimenta minério das unidades basais blendado com limonita ocre, a produção corresponde à capacidade nominal: 45000 tpa Ni. Na segunda fase, em que se alimenta apenas limonita verme- lha, a produção cai para cerca de 16000 tpa Ni.

Para as demais escalas, a vida útil é menor e o perfil de produção é semelhante. A Figura 6 mostra o perfil de produção de Ni metálico para a escala de 120000 tpa Ni.

O consumo de ácido sulfúrico foi obtido a partir de adaptação do consumo específico conforme computado por Marshall e Buarzaiga (2004), partindo-se de um consumo específico de $385 \mathrm{~kg}$ de ácido por tonelada de minério seco alimentada pela lixiviação, que foi ajustado proporcionalmente pela variação dos teores de magnésio e níquel alimentados.

O controle do teor de magnésio e, por conseqüência, do consumo de ácido é feito limitando-se a alimentação de unidades de saprolito e transição, que são blendadas com as limonitas. 
Ruy Lacourt Rodrigues et al.

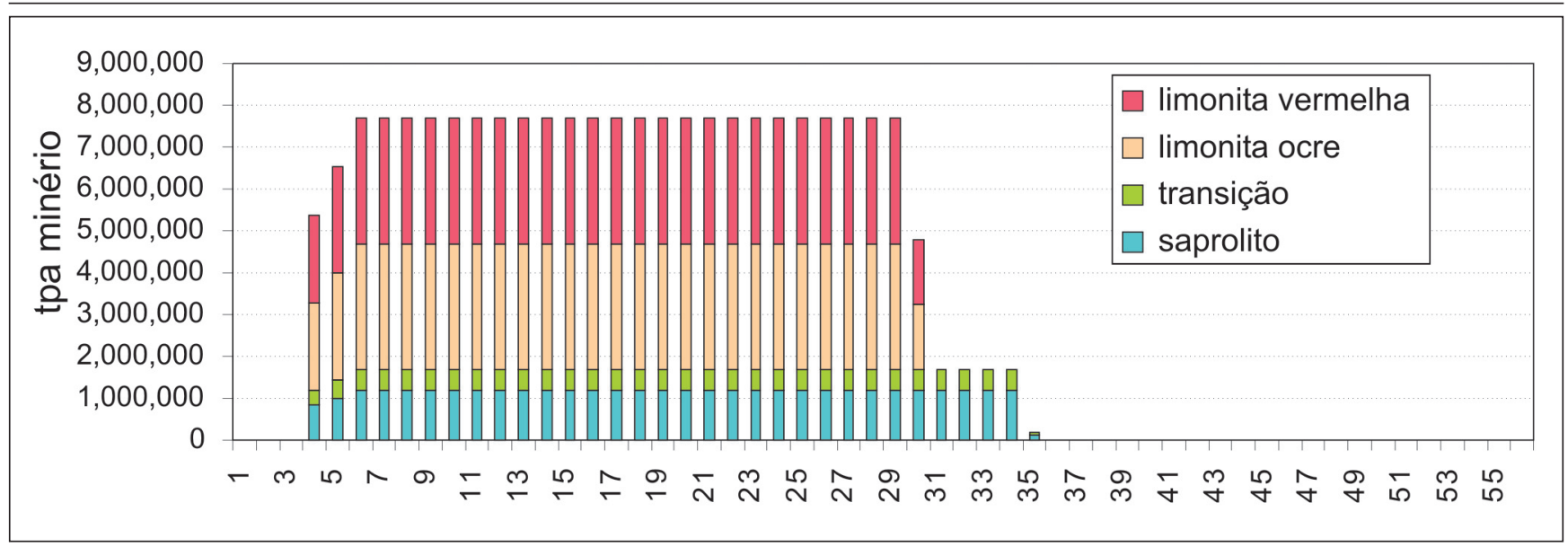

Figura 4 - Perfil de produção - lavra - 45000 tpa Ni.

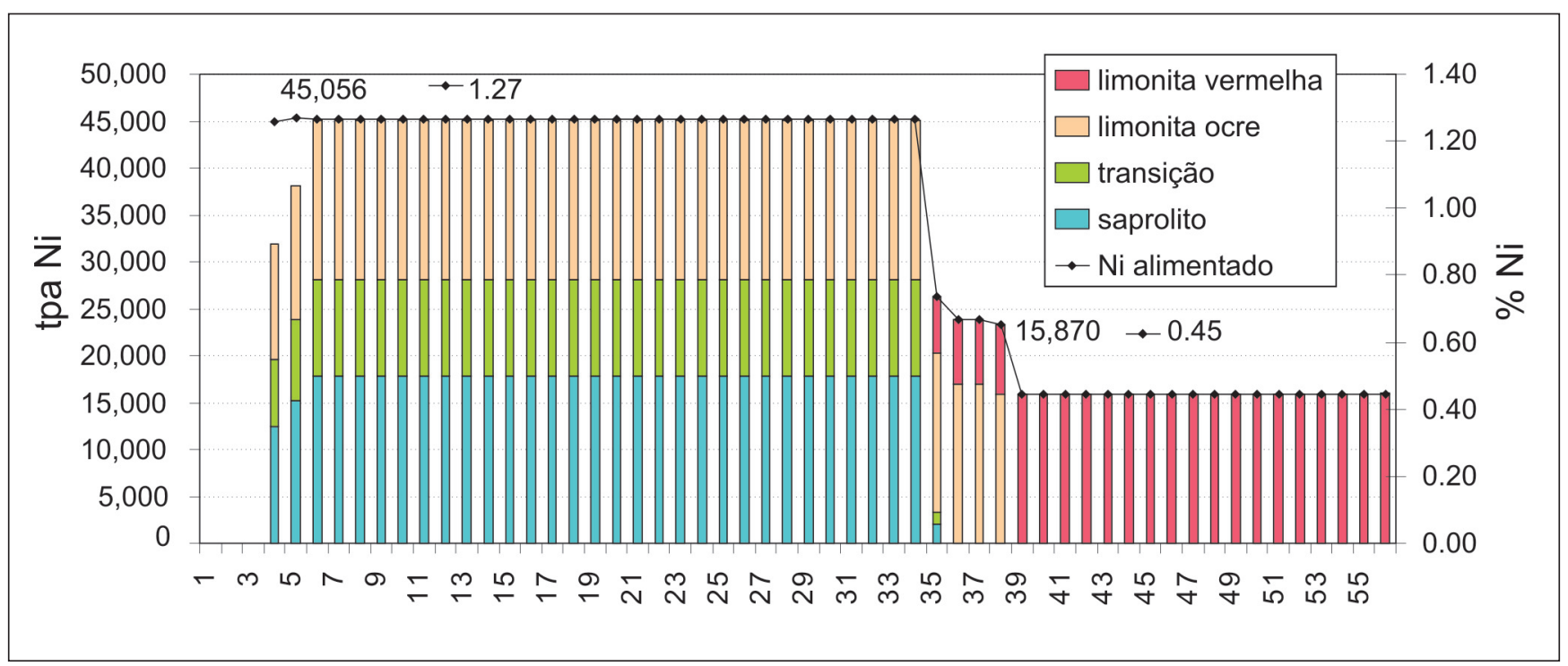

Figura 5 - Ni produzido por origem - 45000 tpa Ni.

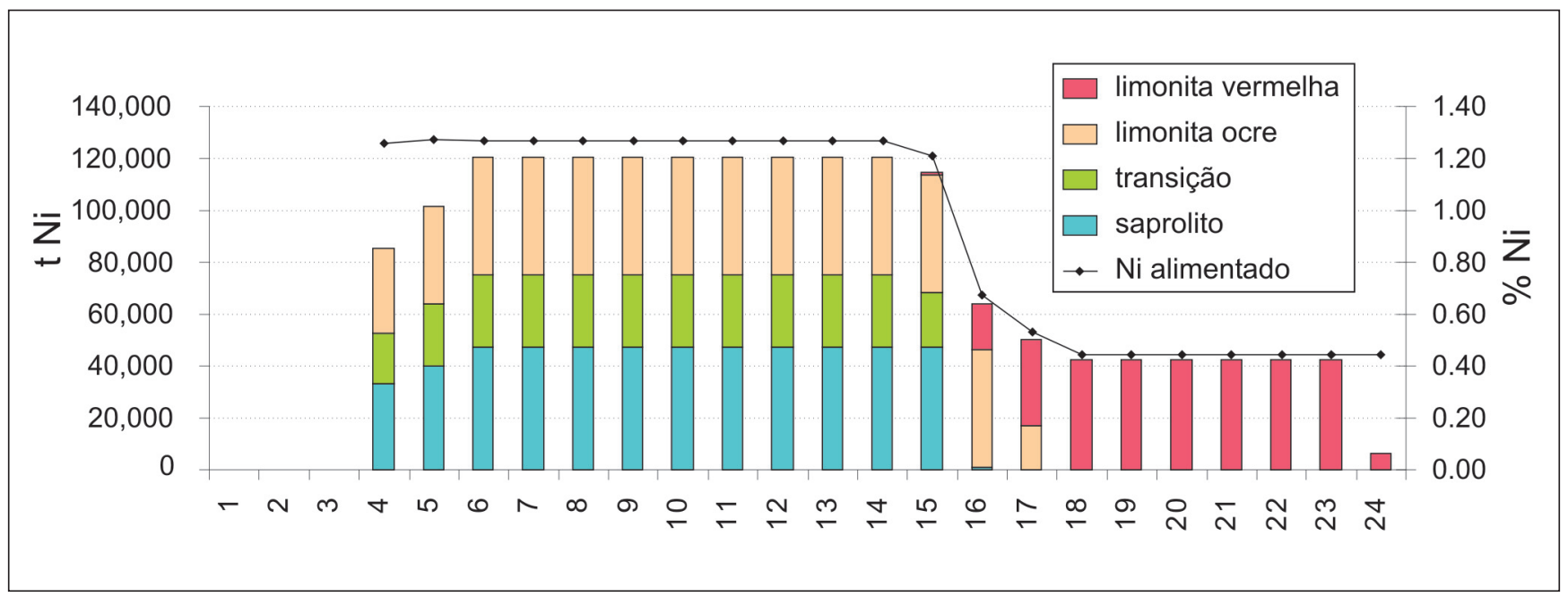

Figura 6 - Ni Produzido por origem - 120000 tpa Ni. 


\section{Conclusão}

A metodologia utilizada para definir o tamanho e as características de qualidade do depósito-tipo e para desenvolver os planos de aproveitamento para as várias escalas assegura aderência ao comportamento provável dos depósitos em desenvolvimento e implementação e permite a avaliação econômica da escala de produção (Rodrigues, 2007) sob condições realistas.

\section{Agradecimentos}

Os autores agradecem ao grupo Vale e à Universidade Federal e Ouro Preto pelo apoio durante o desenvolvimento do projeto de pesquisa, em especial ao geólogo Walter Riehl, por seus comentários sobre a definição das características do depósito.

\section{Referências bibliográficas}

ANACONDA NICKEL. Murrin Murrin Operations - Business Overview - Presentation to Secured Creditors - 15 March 2002. Anaconda Nickel. Disponível na internet $<$ s.n.a $>$. Acesso em: 24 mar. 2002.

ELIAS, M. Nickel laterite deposits: Geological overview, resources and exploitation. In: COOKE, D., PONGRATZ, J. (eds.). Giant ore deposits: Characteristics, genesis and exploration. CODES Special Publication 4. Hobart, Tasmania: Centre for Ore Deposit Research, University of Tasmania, 2002. p. 205-220.

LANE, K.The economic definition of ore. London: Mining Journal Books Ltd, 1988.

MARSHALL, D., BUARZAIGA, M. Effect of magnesium content on sulfuric acid consumption during high pressure acid leaching of laterite ores. In: IMRIE, W. , LANE, D. (eds.). International Laterite Nickel Symposium. Charlotte, NC, U.S.A, Proceedings. Warrendale, PA, USA: TMS (The Minerals, Metals \& Materials Society), 2004. p. 263271.

RODRIGUES, R. Definição de capacidade de um depósito médio de níquel laterítico aproveitado através de rota de lixiviação ácida sob pressão. Ouro Preto: Programa de Pós-Graduação em Engenharia Mineral, Universidade Federal de Ouro Preto, 2007. (Dissertação de Mestrado em Engenharia Mineral), .

USGS - U.S. Department of the Interior. U.S. Geological Survey. Mineral Commodity Summaries 2003 - Nickel: Disponível em: <http://minerals.usgs.gov/minerals/pubs/ commodity/nickel/nickemyb03.pdf $>$ Acesso em: 02 nov. 2005.

Artigo recebido em 07/03/2008 e aprovado em 20/04/2008. 